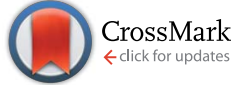

Cite this: RSC Adv., 2015, 5, 45928

Received 18th April 2015

Accepted 13th May 2015

DOI: 10.1039/c5ra07012k

www.rsc.org/advances

\section{Mediator-free biosensor using chitosan capped CdS quantum dots for detection of total cholesterol $\dagger$}

\author{
Hemant Dhyani, ${ }^{\text {*a }}$ Md. Azahar Ali, ${ }^{\text {b Satyendra P. Pal, }}{ }^{\text {a }}$ Saurabh Srivastava, ${ }^{\text {b }}$ \\ Pratima R. Solanki, ${ }^{\star c}$ Bansi D. Malhotra ${ }^{d}$ and Prasenjit Sen ${ }^{a}$
}

\begin{abstract}
We report results of the studies relating to fabrication of an electrochemical mediator-free biosensor platform using in situ synthesized cadmium sulfide quantum dots (CdS QDs) embedded in chitosan (CHIT) via surface functionalization of cholesterol esterase (ChEt) and cholesterol oxidase (ChOx) enzyme molecules. The results of the microscopic studies of CHIT-CdS QDs biocomposite reveal homogeneous dispersion of the embedded CdS QDs in CHIT and specific combinational symmetry of the $\mathrm{S}^{2-}$ rich species CdS QDs, with CHIT and ChOx-ChEt molecules. The electrochemical studies exhibit the enhanced redox activated behavior of $\mathrm{ChOx}$-ChEt molecules which in turn is found to depend on the size of the chitosan capped CdS QDs, facilitating the fast diffusion of electrons from ChOx-ChEt to the electrode surface. The biofunctionalized CHIT-CdS QDs based biosensor platform utilized for the estimation of total cholesterol without using any mediator shows high sensitivity $(0.384$ $\mu \mathrm{A} \mathrm{mM} \mathrm{m}^{-1} \mathrm{~cm}^{-2}$ ) in a wide detection range $(0.64-12.9 \mathrm{mM})$ of total cholesterol. This Cds QDs based platform has enormous possibilities for the development of biosensors for clinical diagnostics.
\end{abstract}

\section{Introduction}

Quantum dots (QDs) are an appealing choice in the field of biological applications due to their unique electrochemical and photophysical properties. ${ }^{1-6}$ The well known tunable optical and surface functionalization properties of both QDs and QDs based biocomposites, allow them to be water soluble and to be employed as targets for detection of specific biomolecules. The biocomposites formation via biofunctionalization of QDs in conjunction with proteins, DNA, peptides, enzymes, polymers etc., has evolved over the past decade and is thus of growing interest and innovation. ${ }^{7-10}$ Efforts are also being made for applications of QDs in live cells, in vivo imaging, labeling, sensing of biological and as environmental elements. ${ }^{11-14}$

QDs used in bio-applications are mostly colloidal nanocrystals and hence their synthesis requires surface functionalization with hydrophilic ligands that serve as a point of chemical attachment for biomolecules. Moreover, functionalization can

${ }^{a}$ School of Physical Sciences, Jawaharlal Nehru University, New Delhi-110067, India. E-mail: kashi.hemant@gmail.com

${ }^{b}$ Department of Science and Technology Centre on Biomolecular Electronics, National Physical Laboratory, Dr K. S. Krishnan Marg, New Delhi-110012, India

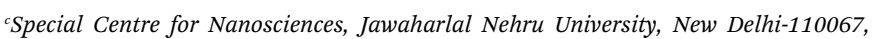
India. E-mail: pratimarsolanki@gmail.com

${ }^{d}$ Department of Biotechnology, Delhi Technological University, Shahabad Daulatpur, Main Bawana Road, Delhi 11042, India

$\dagger$ Electronic supplementary information (ESI) available. See DOI: $10.1039 / \mathrm{c} 5 \mathrm{ra} 07012 \mathrm{k}$ protect the QDs surface from deterioration in a biological medium while preventing them from agglomeration. Different strategies of capping and dispersion of QDs have been discussed and summarized ${ }^{15}$ and it has been observed that the barrier to further development of these interesting composite nanocomposites continues to be the lack of efficient chemical methods with intimate control over different parameters for attachment of biomolecules to QDs. ${ }^{16}$

Till date, biofunctionalization has been reportedly accomplished via tagging, labeling or ligand exchange using optical fluorescence properties of different sensing strategies and only a few have been reported via electrochemical techniques. ${ }^{17,18}$ CdS in presence of $\mathrm{S}^{2-}$ ions may perhaps provide excellent electrocatalytic redox behaviour for fabrication of desired electrochemical based QDs based electrode. ${ }^{19,20}$ As an indicator, our experimental studies on CdS based electrode system have shown that homogeneous hexagonal crystalline surfaces of QDs may yield improved enzyme immobilization. ${ }^{21}$ In this context, polyaniline-CdS quantum dots nanocomposite has been found to exhibit increased electron transfer. ${ }^{22}$ The conjugation of QDs with a polymer may thus play an important role for the fabrication of a more stable, biocompatible and easily synthesized colloidal matrix with a controllable access towards enzymematrix orientation. The organic-inorganic nanocomposites have recently aroused much attention. ${ }^{23}$ It has been recently predicted that QDs-polymer nanocomposites may be utilized for different electrochemical and optical applications. ${ }^{23,24}$ 
Chitosan (CHIT), (1,4)-2-amino-2-deoxy- $\beta$-D-glucan, is a natural biopolymer produced by deacetylation of chitin. Due to its good chelating ability and the presence of high content of amino $\left(-\mathrm{NH}_{2}\right)$ and hydroxyl $(-\mathrm{OH})$ groups, CHIT offers biocompatibility, hydrophilicity, remarkable affinity to biomolecules including DNA and protein and hence it may serve as a suitable matrix to synthesize semiconductor quantum dots and prevent them from agglomeration. Many attempts have been made to explore the properties of CHIT-QDs composite material. ${ }^{25-28}$ Recent reports have revealed highly efficient photocatalytic activity resulting in enhanced interest in the bioconjugation of QDs with CHIT and its applications in biosensing. ${ }^{29-33}$

In this article, we report results of the studies relating to the synthesis of the bioconjugated CHIT-CdS QDs nanomatrix obtained by immobilizing cholesterol esterase (ChEt) and cholesterol oxidase (ChOx) for detection of total cholesterol. This CHIT-CdS QDs based bioelectrode shows excellent electroactive properties. Besides this, the homogeneous and stable in situ formation of CdS QDs embedded in the CHIT matrix provides favorable environment for direct electron transfer of electrons leading to enhancement in the biocatalytic behaviour of enzyme molecules.

\section{Materials and methods}

\subsection{Chemical and reagents}

Cholesterol oleate solution (500 $\mathrm{mg} \mathrm{dL}^{-1}$ ) is dissolved in $1 \%$ polidocanol (Brij) as a surfactant by heating/stirring resulting in clear and colourless suspension and final volume is made by addition of $0.9 \% \mathrm{NaCl}$ solution. Further, different concentrations of cholesterol oleate varying from $25-500 \mathrm{mg} \mathrm{dL}^{-1}$ have been prepared in $0.9 \% \mathrm{NaCl}$ solution. Cholesterol oxidase (ChOx), cholesterol esterase (ChEt) and cholesterol oleate, cadmium chloride $\left(\mathrm{CdCl}_{2}\right)$, chitosan (CHIT) have been purchased from Sigma Aldrich, USA.

\subsection{Synthesis of CHIT-CdS QDs biocomposite}

The synthesis of CHIT-CdS QDs biocomposite has been carried out under ambient conditions (room temperature and pressure). Firstly, $87.4 \mathrm{mg}$ of cadmium chloride $\left(\mathrm{CdCl}_{2}\right)$ is dissolved in $50 \mathrm{~mL}$ of a $1 \%(\mathrm{v} / \mathrm{v})$ glacial acetic acid solution in MilliQ water, following which $400 \mathrm{mg}$ of CHIT is further added to this solution and the mixture is stirred for next 4 hours to reach a chelating balance between CHIT molecules and $\mathrm{Cd}^{2+}$ ions. After this $1 \mathrm{~mL}$ of aqueous sodium sulfide $\left(\mathrm{Na}_{2} \mathrm{~S}, 7 \mathrm{mg} / 5 \mathrm{~mL}\right)$ is rapidly added drop-wise to the $\mathrm{Cd}^{2+} / \mathrm{CHIT}$ solution and is vigorously stirred with a magnetic stirrer. Different concentrations of $\mathrm{Na}_{2} \mathrm{~S}$ i.e. varying $\mathrm{S}^{2-}$ ion concentrations $\left(\left[\mathrm{S}^{2-}\right]\right)$ in solution have been prepared. After 30 minutes of further stirring, the prepared CHIT-CdS QDs composite with varying $\left[\mathrm{S}^{2-}\right]$ are stored at $4{ }^{\circ} \mathrm{C}$ in the dark.

\subsection{Bioconjugation of CHIT-CdS QDs biocomposite}

For the preparation of enzyme conjugated composite electrode, $10 \mu \mathrm{L}$ solution containing CHIT-CdS QDs is deposited onto the surface of pre-cleaned ITO via drop-casting method. $20 \mu \mathrm{L}$ of the mixed solution of cholesterol oxidase (ChOx) and cholesterol esterase (ChEt) (1: 1 ratio) is spread over the prepared CHIT$\mathrm{CdS} / \mathrm{ITO}$ electrode and kept in a humid chamber for $4 \mathrm{~h}$ and finally stored at $4{ }^{\circ} \mathrm{C}$ when not in use. Prior to use these bioelectrodes are washed 2-3 times properly with phosphate buffer to remove any unbound enzymes from the electrode surface.

\subsection{Instrumentation}

Scanning electron microscopy (SEM, Zeiss EVO 40) and transmission electron microscopy (JEOL JEM-2000 EX) have been used to reveal the formation of CHIT-CdS QDs composite and the immobilization of ChEt-ChOx onto the composite matrix. Spectral studies have been carried out by UV-visible spectrophotometer (model 2200 DPCV, Phoenix), and Fourier transform infra-red (FT-IR) spectroscopy using Perkin-Elmer Spectrophotometer (model "Spectrum BX" using ATR accessory). Electrochemical investigations (CV and EIS) of the various electrodes have been carried out using an Autolab Potentiostat/ Galvanostat (Eco Chemie, Netherlands) in a conventional threeelectrode electrochemical cell consisting of $\mathrm{Ag} / \mathrm{AgCl}$ as the reference electrode and platinum foil as the counter electrode.

\section{Results and discussion}

\subsection{UV-visible studies}

Firstly, the in situ synthesis of CdS QDs embedded into CHIT polymer has been carried out under ambient condition and this composite material is used to fabricate the CHIT-CdS/ITO electrode. Further, the immobilization of ChEt-ChOx enzyme molecules onto composite electrode is performed through physical adsorption as shown in Scheme 1(i). The UV-visible spectra of chitosan, chitosan/Cd ${ }^{2+}$ complex and CHIT-CdS (QDs) composites are shown in Fig. 1(i). A shoulder seen around $300 \mathrm{~nm}$ appears in the spectra of CHIT/ $\mathrm{Cd}^{2+}$ complex (curve b) is associated with the electronic transition of nitrogen on the secondary amide and primary amine groups of chitosan. ${ }^{26}$ The formation of CdS QDs can be inferred since an absorption peak for CHIT-CdS (QDs) composite appears around $425 \mathrm{~nm}$ as compared to that $(515 \mathrm{~nm})$ of bulk CdS (curve c-e). This blue shift in absorption peak is a result of quantum confinement effect and it confirms the formation of CdS QDs in CHITmatrix. $^{34}$ Furthermore in the absorption spectra of CHIT-CdS (QDs) we find the disappearance of the absorption shoulder around $300 \mathrm{~nm}$, indicating the interaction of CdS QDs with the $\mathrm{CHIT}$ at the site of the amino groups. On addition of $\mathrm{Na}_{2} \mathrm{~S}$ to the $\mathrm{Cd}^{2+} / \mathrm{CHIT}$ complex, $\mathrm{S}^{2-}$ ions concentration on the surface of CdS QDs increases resulting in increased in peak intensity indicating enhanced particle size of the composite matrix.

\subsection{Electron microscopic analysis}

The CdS quantum dots are dispersed and appear to be embedded homogeneously in the CHIT matrix as shown in transmission electron microscopy (TEM) images [Fig. 1(ii)]. This uniform distribution explains the mechanism of CdS formation where the hydroxyl rich surface of CHIT binds the $\mathrm{Cd}^{2+}$ ions and 


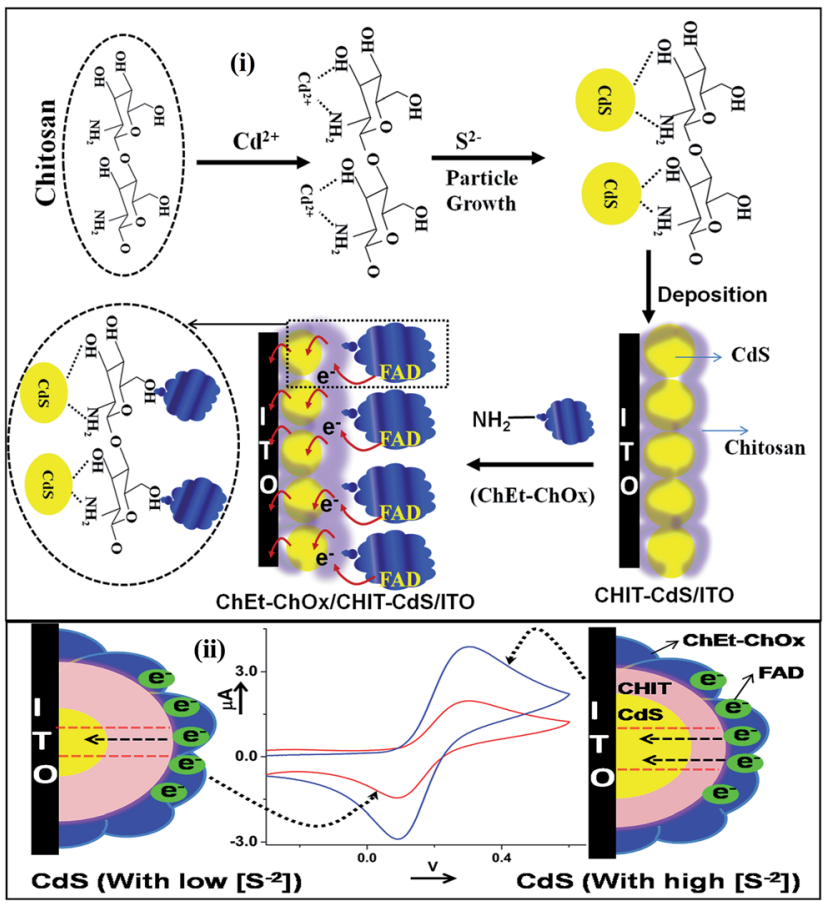

Scheme 1 (i) A pictorial representation of in situ synthesis of CdS QDs in $\mathrm{CHIT}$ biopolymer, where in the $\mathrm{S}^{2-}$ produced combines with $\mathrm{Cd}^{2+}$ chelated in CHIT to form the yellow colored CdS nanocrystals appear in the CHIT solution and biofunctionalization of ChEt-ChOx enzyme on the surface of CHIT-CdS. (ii) Schematic explains the phenomenon for enhanced redox behavior in enzyme molecules while immobilized onto CHIT-CdS/ITO with varying $\left[\mathrm{S}^{2-}\right]$. provides well distributed nucleation centers ${ }^{35}$ and the dropwise addition of $\mathrm{Na}_{2} \mathrm{~S}$ produces $\mathrm{S}^{2-}$ ions which quickly react with $\mathrm{Cd}^{2+}$ ions to form CdS QDs distributed uniformly in the biopolymer matrix. Fig. 1(iii and iv) shows the images following immobilization of ChEt-ChOx onto the surface of the CHITCdS QDs composite with high $\left[\mathrm{S}^{2-}\right]$ and low $\left[\mathrm{S}^{2-}\right]$, respectively, where the homogeneous dispersion of embedded dots can be observed more clearly than that of CHIT-CdS QDs composite. The dispersion of CdS quantum dots remains same on incorporation of enzyme molecules as seen in Fig. 1(iii and iv). Thus, chitosan plays an important role in uniform dispersion of CdS quantum dots as well as provide an affinity with enzyme molecules. For enzyme modified composite the well dispersed CdS QDs of size around 4-7 nm with higher $\left[\mathrm{S}^{2-}\right]$ can be easily seen in the high resolution micrograph (inset: Fig. 1(iii)) and for lower $\left[\mathrm{S}^{2-}\right]$, CdS QDs appear around 2-4 nm (inset: Fig. 1(iv)). This reveals the affinity of QDs modified CHIT matrix with ChOx and ChEt, where the active surface of QDs serves as a better immobilization platform for the enzyme molecules.

\subsection{X-ray diffraction and SEM studies}

Due to highly crystalline nature of the bioconjugate composite film, the sharp and intense peaks are obtained in the X-ray diffraction (XRD) pattern of CHIT-CdS QDs composite film (Fig. S1†) indicating successful formation of hexagonal phase of CdS QDs surface or in the inner parts of CHIT. The scanning electron micrograph (SEM) shown in Fig. 2, further supports results of TEM and XRD revealing that the incorporation of CdS QDs with CHIT remains complete. Consequently, the surface of

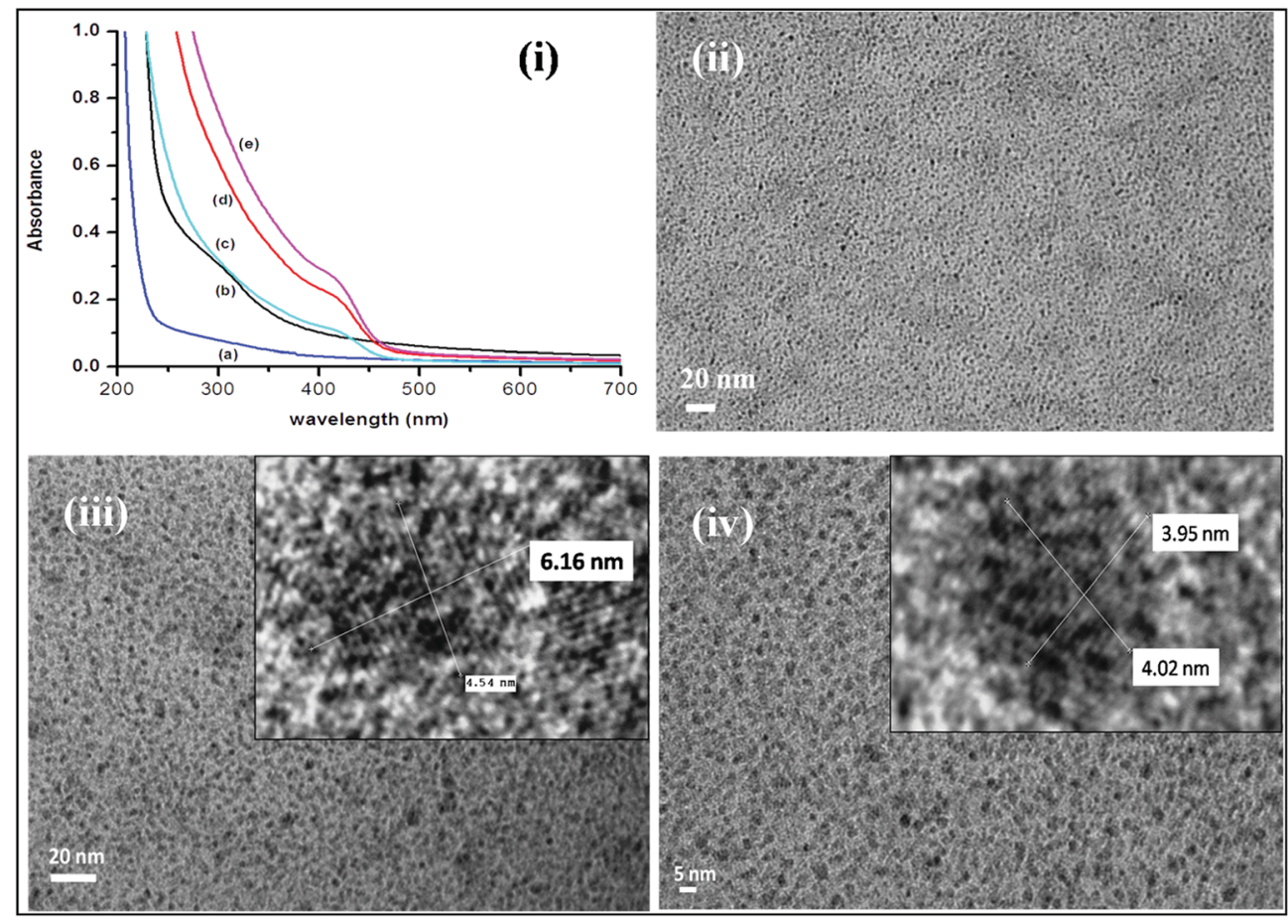

Fig. 1 (i) UV-visible absorption spectra of (a) CHIT, (b) chitosan-Cd ${ }^{2+}$ complex (c-e), CHIT-CdS QDs composite with increasing concentration of $\mathrm{S}^{2-}$ ions. (ii) TEM images of $\mathrm{CHIT-CdS}$ (QDs) composite, (iii) $\mathrm{ChEt}-\mathrm{ChOx} / \mathrm{CHIT-CdS}$ with higher $\left[\mathrm{S}^{2-}\right.$ ] and (iv) $\mathrm{ChEt}-\mathrm{ChOx} / \mathrm{CHIT-CdS}$ composite with lower $\left[\mathrm{S}^{2-}\right]$. 

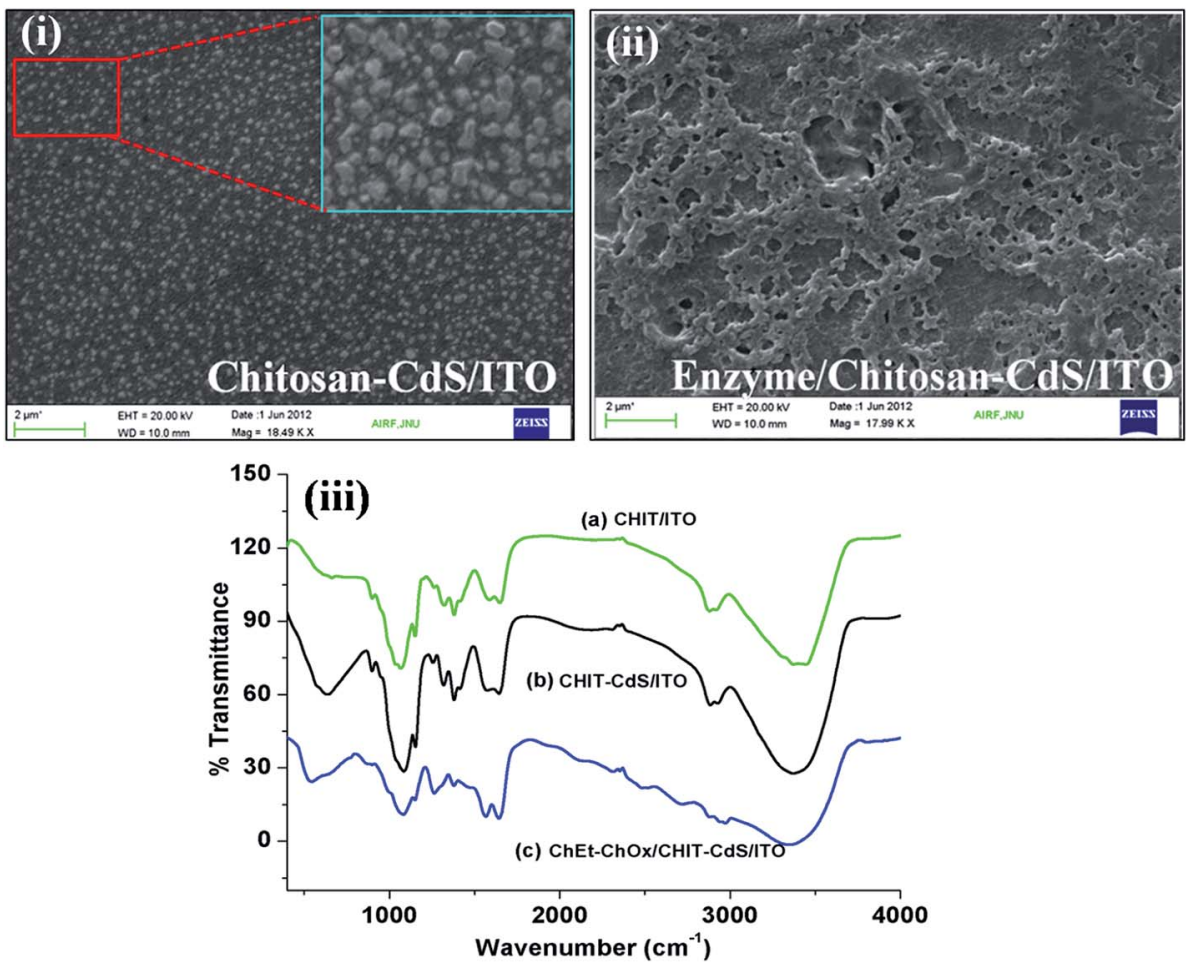

Fig. 2 (i) SEM images of CHIT-CdS/ITO film, (ii) ChEt-ChOx/CHIT-CdS/ITO film and (iii) FT-IR spectra of various fabricated electrodes.

the film becomes homogeneous and the well-dispersed globular structures in the nanometer scale can be easily seen, which confirms that the CHIT serves as a template and helps in the uniform dispersion of the QDs. The enlarged image shown in the inset of Fig. 2(i) indicates that the CHIT-CdS QDs composite film has a combination of small and large CHIT-CdS globules, which provides a compatible substrate for the immobilization of bio-molecules. ${ }^{29}$ The larger sized CHIT-CdS globules are perhaps due to agglomeration of CHIT-CdS composite during the formation of film on ITO via drop casting. Furthermore, the effect of immobilization of the ChOx-ChEt can be seen in Fig. 2(ii) where the surface of the electrode gets covered by the ChOx-ChEt.

\subsection{Fourier transform infrared studies}

To confirm the interaction between the CHIT, CdS QDs and ChOx-ChEt molecules, the FT-IR studies have been conducted [Fig. 2(iii)]. The broad peak centered around $3430 \mathrm{~cm}^{-1}$ in the spectra of CHIT/ITO arises due to stretching of the hydroxyl (O$\mathrm{H})$ and amino $(\mathrm{N}-\mathrm{H})$ groups that become intense and is noticeably shifted to $3375 \mathrm{~cm}^{-1}$ for CHIT-CdS/ITO, indicating strong interaction between these groups and CdS QDs. ${ }^{36,37}$ Further, broadening of the peaks in ChEt-ChOx/CHIT-CdS film observed around $3360 \mathrm{~cm}^{-1}$ and $1089-1564 \mathrm{~cm}^{-1}$ due to the addition of carbonyl and amino groups, confirms the binding of enzyme with the CHIT-CdS QDs composite. The peak of Cd-S in CHIT-CdS/ITO at $635 \mathrm{~cm}^{-1}$ is found to be suppressed, and an intense peak appears at $550 \mathrm{~cm}^{-1}$. These results indicate electrostatic interactions between ChOx-ChEt and the surface of
CdS QDs, indicating the ChOx-ChEt binding with CHIT such that its orientation remains parallel for every side of the hexagonal phases of CdS QDs.

\subsection{Electrochemical properties and mediator-free detection}

The well-defined oxidation and reduction peaks with peak-topeak separation of $0.37 \mathrm{~V}$ are shown in cyclic voltammetry (CV) studies (Fig. 3(i)) of fabricated electrodes in phosphate buffer (PBS) in the potential range, $-0.5 \mathrm{~V}$ to $+0.6 \mathrm{~V}$. CHIT modified bare ITO electrode shows higher peak (anodic/ cathodic) currents (curve a) as compared to that of ChEtChOx/CHIT/ITO bioelectrode (curve b) due to insulating nature of the enzymes that hinder electron transfer towards the electrode. On incorporation of CdS QDs into the CHIT network, the anodic peak current decreases (curve c) because of semiconducting nature of CdS that again restricts electron flow due to decreased electron transfer. The peak current increases largely $(5.82 \mu \mathrm{A})$ in case of the ChEt-ChOx modified CHIT-CdS electrode (curve d) when compared to that of the CHIT-CdS electrode $(1.55 \mu \mathrm{A})$. This is attributed to the fact that CdS communicates to the redox active 'flavin adenine dinucleotide' (FAD) sites of enzymes leading to lower tunneling distance of electrons towards current collector. Alternately, CdS QDs contain $\mathrm{S}^{2-}$ ions which exhibit excellent electrocatalytic redox behavior and act as a mediator and establish an electronic path between the enzyme active sites (FAD) and the electrode that perhaps results in increased transport of electrons towards the electrode. Furthermore, the relative response of electrodes for the enzyme molecules with the different concentration of $\mathrm{S}^{2-}$ 

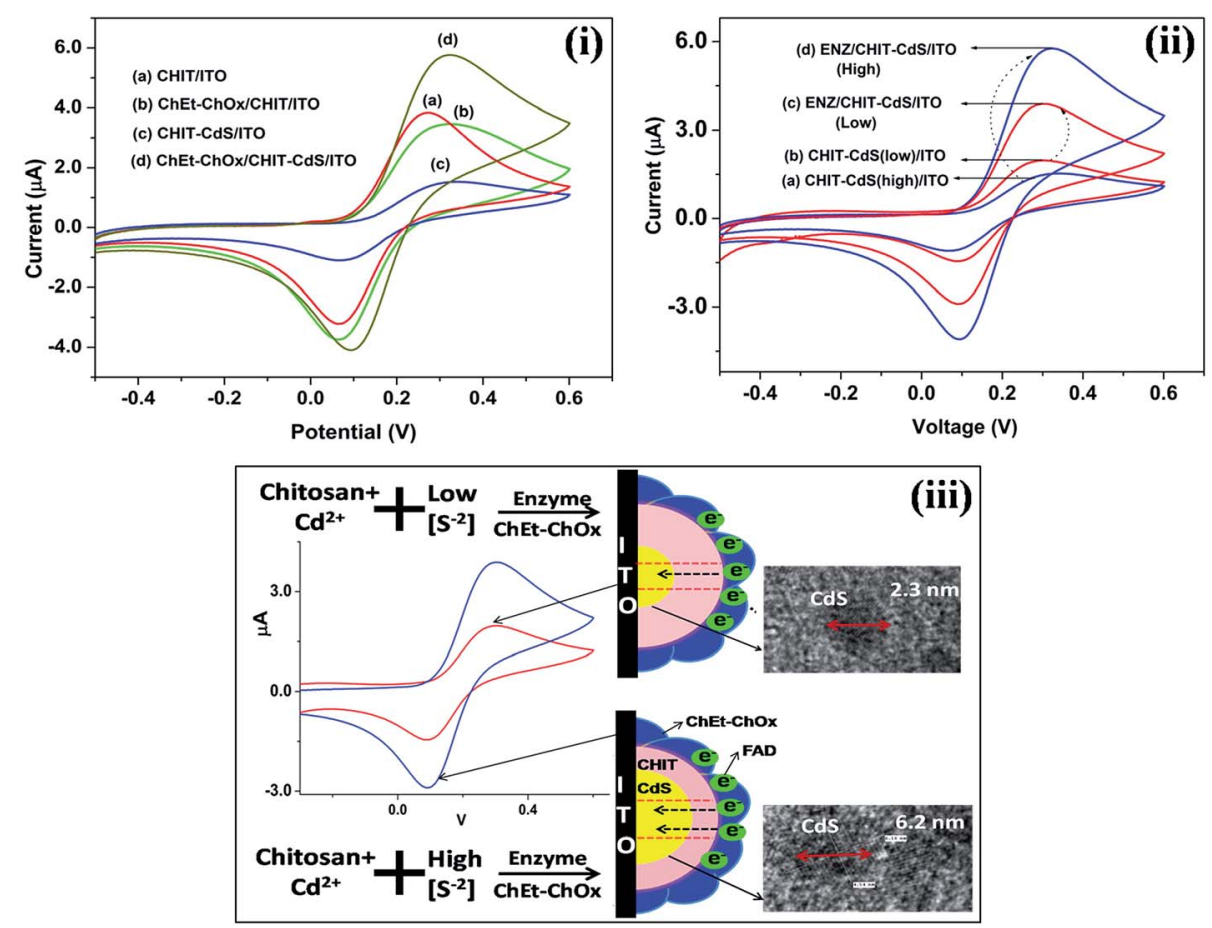

Fig. 3 (i) Cyclic voltammogram (CV) of the different electrodes in PBS (50 mM, pH7.4, 0.9\% NaCl), (ii) CV of (a) CHIT-CdS/ITO (with high [S ${ }^{2-}$ ]),

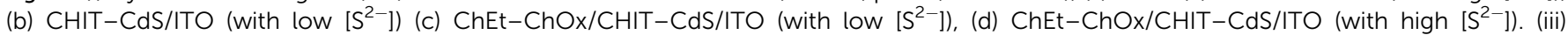
Schematic representation of CV responses for ChEt-ChOx/CHIT-CdS bioelectrode with small and large CdS QDs.

ions is shown in Fig. 3(ii). Curve (a) shows the relatively lower current value $(1.47 \mu \mathrm{A})$ for CHIT-CdS consisting of higher $\left[\mathrm{S}^{2-}\right]$ in CdS QDs as compared to the electrode having lower $\left[\mathrm{S}^{2-}\right]$ in CdS $(1.95 \mu \mathrm{A})$ (curve b), which may be attributed to the semiconducting nature of CdS which hinders electron transfer towards the electrode. However, after incorporation of ChEtChOx, the current increases to $5.74 \mu \mathrm{A}$ (for high $\left[\mathrm{S}^{2-}\right]$, curve d) as compared to electrode having low $\left[\mathrm{S}^{2-}\right]$ (curve c) in CdS $(3.9 \mu \mathrm{A})$. This confirms the current dependence on the concentration of $\mathrm{S}^{2-}$ ions and is also observed in the CV studies for the ChEtChOx/CHIT-CdS as a function of $\left[\mathrm{S}^{2-}\right]$ (Fig. S2 $\dagger$ ) that the current increases linearly with increasing $\left[\mathrm{S}^{2-}\right]$. This may be due to increased $\left[\mathrm{S}^{2-}\right]$ on the surface of QDs resulting in increased size of CdS QDs, which interact with more proximity to the active sites (FADs) of the immobilized enzyme. The reduced electron tunneling distance between FAD and surface of CdS QDs results in enhanced electron diffusion from redox active sites towards electrode surface [Fig. 3(iii) and Scheme 1(ii)].

The charge transfer resistance $\left(R_{\mathrm{ct}}\right)$ of the enzyme electrode is found to be equivalent to that of CHIT/ITO and is lower than that of CHIT-CdS/ITO as observed in electrochemical impedance spectroscopy (EIS) study (Fig. S3†), This results in an enhanced redox peak current. This confirms that favorable and parallel orientation of enzymes active sites towards the homogeneous dispersed hexagonal phase CdS QDs provide a unique combinational symmetry of 'enzyme-QDs-polymer' which makes this ChEt-ChOx/CHIT-CdS bioelectrode 'redox activated' and perhaps facilitates the electrons from enzymes to electrode via CHIT-CdS matrix.
The observed redox peak increment for the bioelectrode has been observed with increasing $\left[\mathrm{S}^{2-}\right]$ in the range from $0.36 \mathrm{mM}$ to $1.44 \mathrm{mM}$. Further increase in $\left[\mathrm{S}^{2-}\right]$ causes gradual decay in the redox peak current, indicating saturation of the QDs surface. It appears that abundance of $\left[\mathrm{S}^{2-}\right]$ disturbs the symmetry and hinders the electron transportation. Thus, optimized concentration of CdS with CHIT based bioelectrode, that not only electrocatalyzes enzymes but also acts as mediator, has been further used for biosensing performance, leading to mediator-free cholesterol biosensor and facilitates direct electrochemistry. The effect of scan rate on CV studies of enzyme modified electrode reveals surface controlled electrochemical diffusion process (Fig. S4 $\dagger$ ). The electrochemical response of the ChEt-ChOx/CHIT-CdS bioelectrode has been carried out with successive addition of cholesterol oleate concentration [25-500 mg dL $\mathrm{d}^{-1}$ ] at a scan rate of $30 \mathrm{mV} \mathrm{s}^{-1}$ in PBS [Fig. 4(i)]. The anodic peak current increases sharply with increased cholesterol oleate concentration. The cholesterol oleate first reacts with ChEt to form cholesterol and fatty acids. Further, cholesterol reacts with ChOx to produce cholesterol-4-ene-3-one and $\mathrm{H}_{2} \mathrm{O}_{2}$. Again $\mathrm{H}_{2} \mathrm{O}_{2}$ is oxidized to $\mathrm{H}_{2} \mathrm{O}$ and $\mathrm{O}^{-}$with release of electrons. This mediator-free sensor towards detection of cholesterol shows increased linearity as $1.29-12.93 \mathrm{mM}$, lower detection limit as $0.47 \mathrm{mM}$ with improved sensitivity $0.384 \mu \mathrm{A}$ $\mathrm{mg}^{-1} \mathrm{dL} \mathrm{cm}^{-2}$ and correlation coefficients $r^{2}=0.992$ [Fig. 4(ii)]. The value of the enzyme-substrate kinetics parameter (Michaelis-Menten constant, $K_{\mathrm{m}}$ ) is found to be $0.39 \mathrm{mM}$ using the Lineweaver-Burk plot. This lower $K_{\mathrm{m}}$ value indicates high affinity of the bioelectrode towards for cholesterol oleate and is 

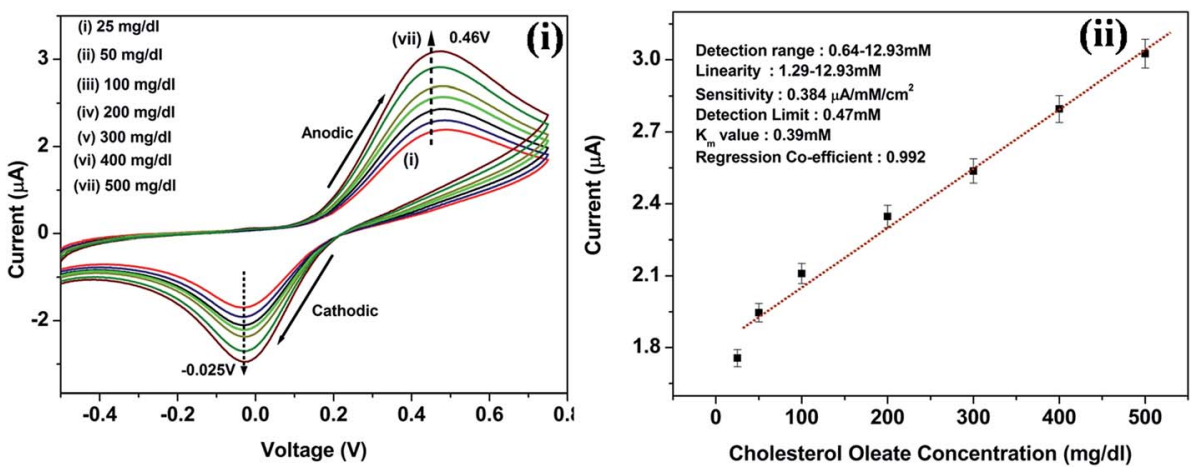

Fig. 4 (i) Electrochemical response of the ChEt-ChOx/CHIT-CdS/ITO bioelectrode at different concentration (25 to $500 \mathrm{mg} \mathrm{dL}^{-1}$ ) of cholesterol oleate in PBS (50 mM, pH 7.0, $0.9 \% \mathrm{NaCl}$ ) and (ii) calibration plot derived from CV measurements at $0.04 \mathrm{~V}$ as a function of cholesterol concentration.

attributed to strong conjugation of ChEt-ChOx with CHIT-CdS matrix. The mediator-free sensor achieves $95 \%$ of the steadystate current in less than $5 \mathrm{~s}$ indicating fast electron exchange between the ChEt-ChOx and CHIT-CdS. Table S5 (ESI†) compares results of this enzyme bioelectrode for cholesterol detection with those reported in literature.

\section{Conclusions}

We have demonstrated a novel platform comprising of the unique combination of 'ChEt-ChOx/CHIT-CdS QDs' for the application of electrochemical biosensor. The size dependent CdS QDs have been prepared and optimized with the CHIT polymer to improve stability, together with a bioactive homogeneous colloidal solution of the composite material for electrochemical applications without using any external deposition technique. The bioconjugation of enzyme molecules with CHIT-CdS composite increases the electrochemical behaviour due to enhanced redox activation of CHIT-CdS with enzyme molecules. The redox activity with enzyme molecules occurs due to the specific combinational symmetry of $\mathrm{S}^{2-}$ rich species CdS QDs, with chitosan, and enzyme molecules which activate the redox active sites (FADs) and facilitate a path for transferring the electrons from enzyme to electrode via CHIT-CdS matrix. CHIT stabilizes the CdS QDs and hence provide more efficient electrochemical behavior. This specific property of the bioconjugation has been utilized for the successful detection of total cholesterol with high linearity and low $K_{\mathrm{m}}(0.39 \mathrm{mM})$. Therefore, the controlled and easy synthesis of such 'enzymeQDs-polymer' system is likely to lead to a more efficient and stable platform in bio-nanocomposite formation for many other electrochemical applications.

\section{Acknowledgements}

We thank Advanced Instrumentation and Research Facility, JNU, New Delhi for the TEM, XRD and SEM analysis. Hemant Dhyani, Md. Azahar Ali, Saurabh Srivastava and Satyendra Prakash Pal thank CSIR-India for the award of Research Fellowships. We are thankful to Dr V. V. Agrawal, M. K. Pandey,
NPL, New Delhi for valuable discussions and Director NPL, for the research facilities.

\section{References}

1 J. M. Klostranec and W. C. W. Chan, Adv. Mater., 2006, 18, 1953.

2 F. Zhang, Z. Ali, F. Amin, A. Riedinger and W. J. Parak, Anal. Bioanal. Chem., 2010, 397, 935.

3 R. Gill, M. Zayats and I. Willner, Angew. Chem., Int. Ed., 2008, 47, 7602.

4 K. E. Sapsford, T. Pons, I. L. Medintz and H. Mattoussi, Sensors, 2006, 6, 925.

5 K. Boeneman, B. Mei, A. Dennis, G. Bao, J. R. Deschamps, H. Mattoussi and I. L. Medintz, J. Am. Chem. Soc., 2009, 131, 3828.

6 H. Mei, J. Tian, H. T. Lu, L. X. Weng and L. H. Wang, Talanta, 2010, 82, 997.

7 N. Hildebrandt, ACS Nano, 2011, 5, 5286.

8 K. Boeneman, J. R. Deschamps, S. B. White, D. E. Prasuhn, J. B. B-Canosa, P. E. Dawson, M. H. Stewart, K. Susumu, E. R. Goldman, M. Ancona and I. L. Medintz, ACS Nano, 2010, 4, 7253.

9 H. Jiang and H. Ju, Chem. Commun., 2007, 404.

10 C. W. Kuo, D.-Y. Chueh, N. Singh, F.-C. Chien and P. Chen, Bioconjugate Chem., 2011, 22, 1073.

11 H. Mattoussi, G. Palui and H. B. Na, Adv. Drug Delivery Rev., 2012, 64, 138.

12 H. Kuang, Y. Zhao, W. Ma, L. Xu, L. Wang and C. Xu, Trends Anal. Chem., 2011, 30, 1620.

13 X. Michalet, F. F. Pinaud, L. A. Bentolila, J. M. Tsay, S. Doose, J. J. Li, G. Sundaresan, A. M. Wu, S. S. Gambhir and S. Weiss, Science, 2005, 307, 538.

14 J. Zhang, Y. Wan, Y. Li, Q. Zhang, S. Xu, H. Zhu and B. Shu, Environ. Pollut., 2011, 195, 1348.

15 I. L. Medintz, H. T. Uyeda, E. R. Goldman and H. Mattoussi, Nat. Mater., 2005, 4, 435.

16 I. Medintz, Nat. Mater., 2006, 5, 842.

17 J. Zhou, H. Huang, J. Xuan, J. Zhang and J.-J. Zhu, Biosens. Bioelectron., 2010, 26, 834. 
18 L. Jianyun, H. Qianmin, W. Xianxiang, L. Zhen and C. Huaping, Prog. Chem., 2010, 22, 2179.

19 Y. Li, V. P. Kotzeva and D. J. Fray, Mater. Lett., 2006, 60, 2743. 20 H. Zhou, X. Gan, T. Liu, Q. Yang and G. Li, J. Biochem. Biophys. Methods, 2005, 64, 38.

21 H. Dhyani, M. A. Ali, M. K. Pandey, B. D. Malhotra and P. Sen, J. Mater. Chem., 2012, 22, 4970.

22 H. Dhyani, C. Dhand, B. D. Malhotra and P. Sen, J. Biosens. Bioelectron., 2012, 3, 1.

23 P. K. Singh, K. W. Kim and H.-W. Rhee, Electrochem. Commun., 2009, 11, 1247.

24 Z. Zhao, M. Arrandale, O. V. Vassiltsova, M. A. Petrukhina and M. A. Carpenter, Sens. Actuators, B, 2009, 141, 26.

25 Z. Li, Y. Du, Z. Zhang and D. Pang, React. Funct. Polym., 2003, $55,35$.

26 J. Dilag, H. Kobus and A. V. Ellis, Forensic Sci. Int., 2009, 187, 97.

27 S. Lai, X. Chang and C. Fu, Microchim. Acta, 2009, 165, 39.
28 H.-T. Lian, B. Liu, Y.-P. Chen and X.-Y. Sun, Anal. Biochem., 2012, 426, 40.

29 R. Jiang, H. Zhu, J. Yao, Y. Fu and Y. Guan, Appl. Surf. Sci., 2012, 258, 3513.

30 H. S. Mansur, A. A. P. Mansur, E. Curti and M. V. D. Almeida, J. Mater. Chem. B, 2013, 1, 1696.

31 B. Krajewska, Enzyme Microb. Technol., 2004, 35, 126.

32 G. F. Payne, M. V. Chaubal and T. A. Barbari, Polymer, 1996, 37, 4643.

33 X. Jin, F. Xi, D. Lv, Q. Wu and X. Lin, Carbohydr. Polym., 2011, 85, 786.

34 A. Henglein, Chem. Rev., 1989, 89, 1861.

35 A. M. Balu, J. M. Campelo, R. Luque, F. Rajabi and A. A. Romero, Mater. Chem. Phys., 2010, 124, 52.

36 R. Khan, A. Kaushik, P. R. Solanki, A. A. Ansari, M. K. Pandey and B. D. Malhotra, Anal. Chim. Acta, 2008, 616, 207.

37 V. Ladizhansky, G. Hodes and S. Vega, J. Phys. Chem. B, 1998, $102,8505$. 